\title{
Molecular Deficits Relevant to Concussion Are Prevalent In Football Players Entering the NFL Draft
}

\section{Laura J Kunces ( $\square$ lkunces@thorne.com )}

Thorne Research https://orcid.org/0000-0002-7832-4107

John A Keenan

EXOS

Caleb M Schmidt

Advanced Pattern Analysis \& Countermeasures Group

Michael A. Schmidt

Advanced Pattern Analysis \& Countermeasures Group

Research article

Keywords: BLOOD METABOLITES, PRECISION NUTRITION, FOOTBALL, HUMAN PERFORMANCE, CONCUSSION, TBI

Posted Date: April 19th, 2021

DOl: https://doi.org/10.21203/rs.3.rs-429809/v1

License: (c) (1) This work is licensed under a Creative Commons Attribution 4.0 International License.

Read Full License 


\section{Abstract}

\section{Background}

Factors influencing individual susceptibility to brain acceleration forces or to poor outcomes in brain injury are not well understood. Characterization of blood variants in athletes entering the highly competitive contact environment of professional football, when coupled with longitudinal follow-up of future concussion incidence and trajectory, may provide additional insight into factors that influence brain injury. We observed the metabolic phenotype of collegiate football players entering the 2016 National Football League (NFL) draft. The principal aims were to characterize the molecular status of individual athletes and quantify the prevalence of athletes with multiple concurrent molecular deficits.

\section{Methods}

Blood was taken from 30 elite American collegiate football players seven weeks before the NFL scouting combine and 15-weeks before entering the NFL draft.

\section{Results}

Average results revealed undesirable values in Omega-3 Index (avg \pm std, $4.66 \pm 1.16 \%$ ), AA:EPA fatty acid ratio $(29.13 \pm 10.78)$, homocysteine $(11.4 \pm 3.4 \mu \mathrm{mol} / \mathrm{L})$, vitamin $\mathrm{D}(30 \pm 11.4 \mathrm{ng} / \mathrm{mL})$, and RBC magnesium $(4.1 \pm 0.8 \mathrm{mg} / \mathrm{dL})$. Using sport optimized reference ranges from previously published research, $10 \%$ presented with $3,40 \%$ presented with 4 , and $50 \%$ of athletes presented with 5 undesirable values at once.

\section{Conclusion}

We conclude molecular deficits in this cohort entering the NFL draft were common, with a significant number of athletes presenting with multiple abnormalities, all with relevant influence on brain health and function. This data warrants extensive metabolic phenotyping and prophylactic precision nutrition countermeasures for athletes entering contact environments.

\section{Introduction}

Among sports, American football [1] is associated with one of the highest incidences of concussion, also known as traumatic brain injury (TBI). Modest literature explores the potential role of nutrition in preventing and treating concussions and obtaining consistent results has been elusive [2], and often therapeutic or prophylactic intervention is not coupled to the nutritional status of individuals. This raises an interesting question whether nutritional or metabolic deficits in an individual prior to entering a contact environment adversely influences the clinical trajectory when that individual's brain is exposed to acceleration forces. 
While there are data on the nutritional status of American football players in college and in those playing in the National Football League (NFL), there is little data on athletes in the transition period. We sought to understand the status of molecular markers relevant to concussion by observing collegiate football players and asking two fundamental questions: what is the status of molecular markers central to metabolic networks that might affect concussion incidence and trajectory, and what is the prevalence of athletes with multiple concurrent abnormalities?

\section{Brief introduction of significant markers assessed}

Previous research established the average American's omega-3 (03) index reference range as 2.9\%-12.9\%, with the optimum set at $8 \%$. The average 20 -year-old American is just less than $4 \%[3,4]$. Active-duty military, a cohort not unlike our collegiate athlete cohort, and a reported 03 Index of $3.5 \%$, which is significantly below the U.S. average (4.5\%) and below the ideal target of $8-10 \%$ [5]. A low 03 index is associated with lower cognitive flexibility, lower executive function, mood and personality issues, and altered brain functional assessments [6].

Collegiate athletes loading DHA at $2 \mathrm{~g}, 4 \mathrm{~g}$, and $6 \mathrm{~g}$ per day was associated with a variable, but favorable impact on neurofilament light [7], a sensitive marker of head trauma in cerebrospinal fluid. Recent reviews suggest that optimizing 03 status through dietary loading may protect the brain against numerous sequelae of TBI $[8,9]$.

While there is little data on homocysteine (Hcy) and concussion, there is substantial research on Hcy and cerebrovascular function. A meta-analysis shows a strong correlation between elevated serum Hcy and the pathogenesis of cerebral infarction, suggesting Hcy may be an important biomarker in the early diagnosis and treatment assessment [10]. Hcy has been shown significantly higher in individuals who died as a result of TBI compared to those still alive at the end of a study period [11]. Previously, prevalence of hyperhomocysteinemia in athletes has been upwards of $47 \%$ [12].

The influence of vitamin D (vitD) on brain health has garnered interest, as it modulates neuronal apoptosis, neuroinflammation, oxidative stress, excitotoxicity, and myelin and axon repair [13]. VitD significantly enhances proliferation of neural stem cells (NSCs) and enhances their differentiation into neurons and oligodendrocytes. NSCs treated with 1,25(OH)2D3 show increased expression of brain derived neurotrophic factor (and other neurotrophins), important for neural cell survival and differentiation [14]. Although different standards of adequacy have been defined, substantial research has shown vitD inadequacy is common among NCAA athletes [15], professional athletes, and the average American. Despite this, athletes should maintain at minimum $40 \mathrm{ng} / \mathrm{mL}$ throughout the year to maximize vitD storage in the muscle [16].

Magnesium (Mg) status may also be important in the brain's response to acceleration injury. $\mathrm{Mg}$ is the most widespread metal ion cofactor in humans, supporting over 600 enzymatic reactions [17], including involvement with maintaining heart rhythm, muscular function, blood pressure, immune system function, glucose levels, calcium absorption and other crucial functions. The sole biologically active form of ATP is 
bound to $\mathrm{Mg}$, while $\mathrm{Mg}$ is also an element of ATP synthase, crucial to athletic performance and neural function. Low RBC Mg ( $<4.0 \mathrm{mg} / \mathrm{dL})$ is a common clinical issue among Americans, and it has been suggested athletes need a higher reference range compared to average adults [18].

Since these and other biomarkers are directly related to brain function and structure, it can be assumed abnormalities may influence the response if an athlete encounters acceleration forces. This manuscript is insightful for the multidisciplinary healthcare team of football programs that wish to optimize their current personalized training/nutrition methods.

\section{Materials And Methods}

\section{Subjects}

Elite collegiate American football athletes were recruited for this study within four weeks of completing their collegiate careers. Athletes were from all positions on a team and all athletes were participating in the NFL scouting combine and were hopeful NFL draft picks for 2016.

Each athlete received written and oral descriptions of all procedures, evaluations, time constraints, benefits, and risks, before signing the Institutional Review Board approved consent form. Athletes did not receive any financial compensation for their participation. The study was approved by Compass IRB Ethics Committee for Human Use (00729) and conformed to the Helsinki Declaration on the use of human subjects for research.

\section{Blood Draw}

Blood was taken following enrollment of the study. Athletes reported for a 12-hour fasted morning antecubital vein blood draw performed by a trained phlebotomist. All blood draws were completed between 7:00 and 9:00 AM. Athletes were instructed to drink water liberally throughout the fast. Four milliliters of whole blood was collected in an EDTA tube and shipped overnight for RBC Omega-3 fatty acid composition analysis to OmegaQuant Analytics, LLC (Sioux Falls, SD). The Omega-3 Index is calculated as the sum of EPA and DHA, expressed as percent of total erythrocyte fatty acids. The Trans Fat Index is a measure of Trans-fats percentages, which is considered a direct reflection of dietary Trans fats consumed [4].

For other blood variables, approximately 30 milliliters of blood was taken in respective tubes and immediately processed at the local Quest Diagnostics (Madison, $\mathrm{NJ}$ ). Analytes included a cholesterol panel (total cholesterol, LDL-C, HDL-C, triglycerides), hormones (estradiol, free testosterone, total testosterone, cortisol, DHEA), markers of inflammation (high sensitivity CRP, homocysteine), biomarkers of insulin resistance (serum glucose, serum insulin, glycosylated hemoglobin (HbA1c)), vitamins (vitamin B12, 25-hydroxyvitamin D, folate), and minerals (red blood cell magnesium, calcium, ferritin, zinc). Raw data were returned to researchers via WellnessFX (San Francisco, CA) platform. Normal clinical ranges of 
serum analytes were based on Quest Diagnostics values with optimized ranges for athletes provided by previous research. Glucose and insulin were used to calculate an index of insulin resistance [HOMA-IR].

\section{Observational Variables}

Anthropometrics were taken to assess body mass index: height via tape measure attached to the wall, and body mass with a floor scale, accurate to $\pm 100 \mathrm{~g}$. Body composition was assessed via 7-site ultrasound measurement using the BodyMetrix ${ }^{\mathrm{TM}}$ Pro (IntelaMetrix, Livermore, CA) by a trained registered dietitian.

\section{Statistical Methods}

Thirty male athletes completed blood and anthropometrics with descriptive statistics reporting mean \pm standard deviation (std) in the tables. Frequency and percentage data were presented comparing the number of athletes with $0-5$ of the primary abnormal variants.

\section{Results}

Of the 30-athlete cohort, 21 (70\%) previously attended a college that had a full-time performance staff inclusive of athletic trainers, registered dietitians, and strength and conditioning coaches dedicated to their football program. The characteristics of these 30 elite male American football players are found in Table 1.

Table 1

Characteristics of elite American collegiate football athletes.

\begin{tabular}{|ll|}
\hline & $\mathrm{n}=30$ \\
\hline Age (yr) & $22 \pm 0.9$ \\
\hline Weight (kg) & $110.7 \pm 24.8$ \\
\hline Height (cm) & $188.7 \pm 6.4$ \\
\hline BMI & $30.8 \pm 5.5$ \\
\hline$\%$ Body fat & $16.4 \pm 7.5$ \\
\hline Position (B / S / BS) & $13 / 7 / 10$ \\
\hline Signed contract with the NFL & 25 \\
\hline $\begin{array}{l}\text { B='big' (defensive players, linemen), S= 'skill' (wide receiver, cornerback, safety, return-specialist, } \\
\text { others), BS = big skill' (quarterback, running back, halfback, tight end, and full back). Values are mean } \\
\pm \text { SD. }\end{array}$ \\
\hline
\end{tabular}

\section{Omega-3 Index}


The average 03 Index was $4.66 \%$ (Fig. 1A, Table 3), with only one athlete above the recommended $8 \%$ optimum performance threshold (optimal performance range is considered $8-10 \%$ ) [19].

Table 3

Red blood cell phospholipid fatty acid composition of elite American collegiate football athletes.

\begin{tabular}{|llll|}
\hline & $\mathrm{n}=\mathbf{3 0}$ & \\
\hline & Mean & SD & Range \\
\hline Omega-3 Index (\%) & 4.66 & 1.16 & $2.64-8.07$ \\
\hline Omega-3 Fatty Acids (\%) & 7.18 & 1.31 & $4.86-11.29$ \\
\hline Alpha-Linolenic (18:3n3) & 0.16 & 0.03 & $0.09-0.24$ \\
\hline Eicosapentaenoic (EPA, 20:5n3) & 0.67 & 0.29 & $0.29-1.85$ \\
\hline Docosahexaenoic (DHA, 22:6n3) & 3.99 & 0.94 & $2.18-6.22$ \\
\hline Omega-6 Fatty Acids (\%) & 37.15 & 1.92 & $31.45-41.03$ \\
\hline Linoleic (18:2n6) & 12.96 & 1.51 & $10.61-16.18$ \\
\hline Arachidonic (AA, 20:4n6) & 17.08 & 1.33 & $14.22-19.45$ \\
\hline cis-Monounsaturated Fatty Acids (\%) & 14.52 & 1.03 & $12.95-16.89$ \\
\hline Saturated Fatty Acids (\%) & 40.13 & 1.07 & $37.57-41.74$ \\
\hline Trans Fat Index (\%) & 0.92 & 0.15 & $0.55-1.35$ \\
\hline AA:EPA & 29.13 & 10.78 & $8.2-62.1$ \\
\hline Omega-6:Omega-3 & 5.35 & 1.06 & $2.8-77$ \\
\hline
\end{tabular}

\section{AA:EPA Ratio (Arachidonic Acid:Eicosapentaenoic Acid)}

Red blood cell (RBC) AA content was $17 \%$, the RBC EPA content was $0.67 \%$, and the AA:EPA ratio was found to be 29.13 (standard reference AA:EPA ratio < 5; optimal performance AA:EPA ratio < 3) [20]. (Fig. 1, Table 3) All 30 athletes were significantly above both reference ranges (Fig. 1B).

\section{Homocysteine (Hcy)}

Using the standard reference limit of $11 \mu \mathrm{mol} / \mathrm{L}$, Hcy was elevated in $40 \%$ of athletes upon entering this study (Fig. 1C), despite normal vitamin B12 and folate levels (Table 2). When applying an optimal performance reference limit of $9 \mu \mathrm{mol} / \mathrm{L}$ [21], $90 \%$ of athletes had abnormal Hcy values. 
Table 2

Nutritional blood variables of the elite American collegiate football athletes.

\begin{tabular}{|c|c|c|c|c|}
\hline & & $\mathrm{n}=\mathbf{3 0}$ & & \\
\hline & & Mean & SD & Range \\
\hline Cholesterol Panel & Total Cholesterol (mg/dL) & 156 & 37.1 & $94-254$ \\
\hline & LDL-C (mg/dL) & 93 & 32.2 & $47-185$ \\
\hline & HDL-C (mg/dL) & 50 & 14.7 & $14-76$ \\
\hline & Triglycerides (mg/dL) & 67 & 26.5 & $35-159$ \\
\hline Hormones & Estradiol (pg/dL) & 29 & 7.2 & $15-47$ \\
\hline & Free Testosterone (pg/dL) & 82 & 28.3 & $16-149$ \\
\hline & Total Testosterone (ng/dL) & 511 & 169.4 & $222-972$ \\
\hline & Cortisol ( $\mu \mathrm{g} / \mathrm{dL})$ & 14.6 & 3.3 & $8.3-20.4$ \\
\hline & DHEA-S $(\mu \mathrm{g} / \mathrm{dL})$ & 278 & 95 & $147-488$ \\
\hline Inflammation & hs-CRP (mg/L) & 1.2 & 1.6 & $0.19-8$ \\
\hline & Homocysteine ( $\mu \mathrm{mol} / \mathrm{L})$ & 11.4 & 3.4 & $8.2-27.2$ \\
\hline Insulin Resistance & Serum Glucose (mg/dL) & 73 & 7.2 & $59-88$ \\
\hline & Serum Insulin (mIU/L) & 6.8 & 4.9 & $1.8-22.9$ \\
\hline & HbA1c (\%) & 5.7 & 0.7 & $5.1-9.3$ \\
\hline & HOMA-IR & 1.33 & 1.2 & $0.39-6.28$ \\
\hline Vitamins & Vitamin B12 (pg/mL) & 738 & 213 & $432-1164$ \\
\hline & Serum $(25[\mathrm{OH}] \mathrm{D})(\mathrm{ng} / \mathrm{mL})$ & 30 & 11.4 & $17-76$ \\
\hline & Folate (ng/mL) & 18 & 4.7 & $4.8-25$ \\
\hline Minerals & RBC Magnesium (mg/dL) & 4.1 & 0.8 & $3.2-6$ \\
\hline & Calcium (mg/dL) & 9.5 & 0.3 & $9-10.3$ \\
\hline & Serum Ferritin (ng/mL) & 127 & 69.4 & $11-369$ \\
\hline & Zinc (mcg/dL) & 75 & 10.5 & $55-102$ \\
\hline
\end{tabular}

\section{Vitamin D}

Vitamin D3 (serum 25[OH] D) was below the standard reference range (>30 ng/mL) in $63.3 \%$ of athletes and was below the optimal performance reference range $(40-60 \mathrm{ng} / \mathrm{mL})$ [16]in $83.3 \%$ of athletes (Fig. 1D). This group had one outlier $(76 \mathrm{ng} / \mathrm{mL})$. 


\section{Magnesium (RBC Mg)}

RBC Mg levels were below the standard reference range $(4.5-6.5 \mathrm{mg} / \mathrm{dL})$ in $86 \%$ of athletes and below the loosely defined ([18]) optimal performance reference range $(5.5-6.5 \mathrm{mg} / \mathrm{dL})$ in $90 \%$ of athletes at assessment (mean $=4.1 \mathrm{mg} / \mathrm{dL})$ (Fig. 1E).

\section{Other Analytes}

Other nutrition-related blood variables are presented in Tables 2, 3. On average, athletes presented with a cholesterol panel, fatty acids, and androgen hormone levels within the clinically normal range. Fourteen percent $(n=4)$ presented with a glycosylated hemoglobin $(H b A 1 c)$ at or above $5.7 \%$; however, on average they had normal fasting glucose and insulin. Trans-fatty acids characterized less than $1 \%$ of total fatty acids on average.

\section{Frequency of Undesirable Values}

A frequency analysis of the primary variants is presented in Tables 4 and 5 . Using the standard reference range, $36.7 \%$ of athletes had 3 undesirable values, $40 \%$ athletes had 4 undesirable values, and $16.7 \%$ had 5 undesirable values. Using the sport optimized reference ranges, $10 \%$ of athletes had 3 undesirable values, $40 \%$ of athletes had 4 undesirable values, and $50 \%$ of athletes had 5 undesirable values.

Table 4

Percentage of athletes with baseline levels outside the standard reference and optimal performance reference range.

\begin{tabular}{|c|c|c|c|c|c|}
\hline & $\begin{array}{l}\text { Omega- } \\
3 \text { Index } \\
(\%)\end{array}$ & AA:EPA & $\begin{array}{l}\text { Homocysteine } \\
(\mu \mathrm{mol} / \mathrm{l})\end{array}$ & $\begin{array}{l}\text { Vitamin } \\
\text { D } \\
\text { (ng/ml) }\end{array}$ & $\begin{array}{l}\text { RBC } \\
\text { Magnesium } \\
\text { (mg/dl) }\end{array}$ \\
\hline Total Subjects (n) & 30 & 30 & 30 & 30 & 21 \\
\hline STANDARD REFERENCE VALUE & $8-10$ & 5.0 & $<11$ & $30-50$ & $4.5-6.5$ \\
\hline $\begin{array}{l}\% \text { of athletes with abnormal } \\
\text { values, according to standard } \\
\text { reference ranges }(n)\end{array}$ & $\begin{array}{l}97 \% \\
(29)\end{array}$ & $\begin{array}{l}100 \% \\
(30)\end{array}$ & $40 \%(12)$ & $\begin{array}{l}73 \% \\
(22)\end{array}$ & $81 \%(17)$ \\
\hline $\begin{array}{l}\text { OPTIMAL PERFORMANCE } \\
\text { REFERENCE VALUE }\end{array}$ & $8-10$ & 5.0 & $<9$ & $40-60$ & $5.5-6.5$ \\
\hline $\begin{array}{l}\% \text { of athletes with abnormal } \\
\text { values, according to optimal } \\
\text { performance ranges (n) }\end{array}$ & $\begin{array}{l}97 \% \\
(29)\end{array}$ & $\begin{array}{l}100 \% \\
(30)\end{array}$ & $90 \%(27)$ & $\begin{array}{l}90 \% \\
(27)\end{array}$ & $90 \%(19)$ \\
\hline
\end{tabular}


Table 5

- Frequency of Undesirable Molecular Variants. The table shows the percentage (number) of athletes presenting with $0,1,2,3,4$ or 5 undesirable baseline levels of the five primary analytes found in this

study. This is presented for the purpose of understanding the extent of single vs. multiple converging abnormalities. The analytes include Omega-3 Index (RBC), AA:EPA ratio, homocysteine, serum vitamin D, and RBC magnesium.

\begin{tabular}{|lllllll|}
\hline & $\mathbf{0}$ & $\mathbf{1}$ & $\mathbf{2}$ & $\mathbf{3}$ & $\mathbf{4}$ & $\mathbf{5}$ \\
& Variants & Variants & Variants & Variants & Variants & Variants \\
\hline $\begin{array}{l}\text { Standard reference ranges } \\
(\mathbf{n})\end{array}$ & $0 \%(0)$ & $0 \%(0)$ & $6.7 \%(2)$ & $\begin{array}{l}36.7 \% \\
(11)\end{array}$ & $\begin{array}{l}40 \% \\
(12)\end{array}$ & $\begin{array}{l}16.7 \% \\
(5)\end{array}$ \\
\hline $\begin{array}{l}\text { Optimal performance } \\
\text { ranges (n) }\end{array}$ & $0 \%(0)$ & $0 \%(0)$ & $0 \%(0)$ & $10 \%(3)$ & $\begin{array}{l}40 \% \\
(12)\end{array}$ & $50 \%(15)$ \\
\hline
\end{tabular}

\section{Discussion}

This pilot aimed to examine the initial status of selected molecular biomarkers involved in metabolic networks that may impact the brain response to head injury in a group of elite American football athletes preparing for the NFL draft. The purpose was to understand the extent of essential micronutrient deficits, along with abnormal surrogate markers, such as Hcy and blood lipids. This design helped us explore the likelihood of an athlete having a nutrition or metabolic abnormality while entering the contact environment. Similarly, this study helps lay the groundwork for a precision nutrition approach to athletes in training. Beyond nutrient effects on performance and recovery, the analytes in this study can be viewed in the context of anatomical structure, biological function, and with attention to how their status may affect the trajectory of an acceleration injury to the brain, potentially providing new insights into concussion prevention and management.

The most compelling results are the frequency distribution of undesirable values found in this cohort. Using the optimal performance ranges, there were no athletes with fewer than two abnormalities in blood values. Significantly, $10 \%$ of athletes had 3 undesirable values, $40 \%$ had 4 undesirable values, and $50 \%$ had 5 undesirable values. This suggests multiple abnormal values important to metabolic networks can be found in small cohorts of elite athletes. Considering the role of related molecular networks in brain metabolism and the potentially nonlinear converging impact of multiple abnormalities [22], this argues the case for prophylactic molecular profiling of individual athletes. It is time to consider the roles of these molecules in brain metabolism and in clinical outcomes associated with brain acceleration injury.

These athletes presented with a suboptimal 03 Index after their collegiate season. A study of German elite athletes revealed an 03 Index comparable to our cohort ( $4.97 \pm 1.19 \%$ versus $4.66 \pm 1.16 \%$, respectively) [19]. Lewis et al. compared DHA levels in 800 active military suicide deaths to 800 controls. Suicide risk was $14 \%$ higher per std of lower DHA percentage (OR $=1.14 ; 95 \% \mathrm{Cl}, 1.02-1.27 ; \mathrm{p}<0.03)$. Among men, risk of suicide death was $62 \%$ greater with low serum DHA status (adjusted OR $=1.62 ; 95 \%$ $\mathrm{Cl}, 1.12-2.34)$ [9]. 
In our cohort, the mean AA:EPA ratio of 29.13 was substantially higher than that of average American males (16.2) and the optimum level (<5.1) [20]. Linoleic acid contributes to the AA:EPA ratio and omega6:omega-3 ratio. An a priori paired samples T-test of our data found linoleic acid was significantly lower in athletes who were drafted versus those who were not drafted ( $p \leq 0.05)$. In a study of 170 adults, linoleic acid and arachidonic acid were two of six metabolites that could be used to differentiate between TBI patients with and without cognitive impairment [23].

Homocysteine (Hcy) is an intermediate formed during methionine to cysteine metabolism and is directly dependent upon one-carbon metabolism (B12, folate, betaine, choline). Previous studies have shown excessive Hcy causes vascular endothelium injury, facilitates smooth muscle cell proliferation, accumulates in the blood, and increases the risk of venous thrombosis [24]. Also, elevated Hcy is associated with brain atrophy, silent brain infarcts, and white matter hyperintensity. Such brain vascular changes may have particular relevance to athletes competing in concussion-prone sports.

In a study examining the changes in methionine/homocysteine network, severe TBI decreased methionine, SAM, betaine and 2-methylglycine, as compared to healthy volunteers. Mild TBI also decreased methionine, a-ketobutyrate, 2-hydroxybutyrate, and glycine, though to a lesser degree than the severe TBI group. Of particular interest was a decrease in betaine, a direct methyl donor to Hcy and crucial in the removal of excess Hcy. This further suggests that Hcy may be implicated in TBI outcomes [25].

In our cohort, $90 \%$ showed elevated Hcy (11.4 \pm 3.4 , range 8.2-27.2), which is in accordance with other studies [12]. Elevated Hcy is frequently associated with low B12 or folate. In our cohort, vitamin B12 and folate were clinically normal, which suggests other potential Hcy influencers. VitD binds and activates the vitD receptor, regulating cystathionine- $\beta$-synthase transcription and facilitating the conversion of Hcy to cystathionine [26]. While this relationship is known, vitD and Hcy were not correlated $(r=-0.167, p=0.376)$ in our cohort. Larger studies are needed to understand the full extent to which vitD influences Hcy levels in athletes.

There is little published data on vitD and TBI. However, a study of 353 adults (26.6-48.3 years) seen 0.356.5 months after moderate to severe TBI is informative. TBI adults with vitD deficiency had significantly lower Addenbrooke's Cognitive Examination scores, compared to those who were vitD insufficient and replete $(p=0.003$ and $p=0.034$ respectively). VitD deficiency was also associated with more severe depressive symptoms [27].

VitD influences athletic performance through hundreds of processes, including exercise-induced inflammation, neurological function, cardiovascular health, glucose metabolism, bone health, and skeletal muscle performance including strength and power. In our cohort, $66 \%$ of athletes just left a school above the 37th parallel in the United States where it was the winter season, and time spent outside was likely with full gear or clothing. $97 \%$ of this study's athletes had vitD levels lower than suggested minimum for optimal athletic performance $(50 \mathrm{ng} / \mathrm{mL})$ and minimal risk for CVD $(60 \mathrm{ng} / \mathrm{mL})$ [16]. 
Neuronal Mg concentrations are of central importance in the regulation of N-methyl-d-aspartate (NMDA) receptor excitability. NMDA receptors are essential for neuronal plasticity, excitatory synaptic transmission, and excitotoxicity, therefore playing an important role in developmental plasticity, learning, and memory [17]. $\mathrm{Mg}$ in the brain is seen as crucial to function, though its role in concussion is not definitive. Research has explored the effect of $\mathrm{Mg}$ status pre-injury [28] and the effect of $\mathrm{Mg}$ post-injury [29] with equivocal results. However, Mg treatments have significantly delayed ischemic infarction [30]. In our cohort, Mg depletion may result from inadequate intake, or following intense exercise, stress, or sweating when low plasma volume causes a cellular shift.

Research has proposed essential and conditionally essential micronutrient deficits (or excess) aggregate and spread across molecular networks. An abnormality can have a broad impact on normal function and on response to trauma, and more than one concurring can amplify across molecular networks in ways that may not be linear [22].

There are several limitations with this study including small sample size, absence of a control group, and no intervention phase, but this study design was observational. Also, we examined a smaller pool of (targeted) analytes in this pilot, which limited our ability to more broadly survey molecular pathways and networks for additional physiological risk to these athletes.

\section{Conclusion}

In conclusion, molecular deficits in this cohort entering the NFL draft were common, with a significant number of athletes presenting with multiple abnormalities, all with relevant influence on brain health and function. This data warrants extensive metabolic phenotyping and prophylactic precision nutrition countermeasures for athletes entering contact environments.

This understanding of molecular pathways and networks gives us a novel way to view the vulnerability of the athlete's brain when exposed to acceleration forces. Screening athletes for abnormalities in essential micronutrient and surrogate biomarkers that affect the brain can prophylactically identify molecular pathway and network alterations in individual athletes. Abnormalities can be targeted with personalized precision nutrition and clinical countermeasures to optimize pathways/networks as the athlete enters the contact environment.

\section{Abbreviations}

AA: Arachidonic acid

Avg: average

CVD: cardiovascular disease

DHA: docosahexaenoic acid 
EPA: eicosapentaenoic acid

HbA1c: glycosylated hemoglobin

Hcy: homocysteine

Mg: magnesium

NFL: National Football League

NMDA: N-methyl-d-aspartate

NSCs: neural stem cells

03: omega-3

RBC: red blood cell

Std: standard deviation

TBI: traumatic brain injury

vitD: vitamin D

\section{Declarations}

\section{Ethical Approval and Consent to Participate}

The study was approved by Compass IRB Ethics Committee for Human Use (00729) and conformed to the Helsinki Declaration on the use of human subjects for research. Each athlete received written and oral descriptions of all procedures, evaluations, time constraints, benefits, and risks, before signing the Institutional Review Board approved consent form.

\section{Consent for Publication}

Consent to submit has been received from all co-authors.

\section{Availability of Supporting Data}

Datasets can be available from the corresponding author upon reasonable request.

\section{Competing Interests}

Blood work was supported by WellnessFX, San Francisco, CA. The authors declare no conflict or competing interest. Results of the study are presented clearly, honestly, and without fabrication, falsification, or inappropriate data manipulation. 


\section{Funding}

N/A; Athletes did not receive any financial compensation for their participation.

\section{Author contributions}

LJK and MAS designed the study and wrote the manuscript. LJK was responsible for data collection. JK completed statistical analysis. CMS did post-analysis statistical analysis and manuscript review. All authors approve the final version of this manuscript.

\section{Acknowledgements}

We would like to thank Zung Vu Tran, Ph.D. for his statistical review of the manuscript, and Billy McCamy and Julian C. Schmidt for technical and editorial support.

\section{Authors Information}

Laura J. Kunces: Onegevity Health, 152 W $57^{\text {th }}$ St, New York, New York 10019; Thorne HealthTech, 620 Omni Drive, Summerville, SC 29483

John Keenan: EXOS, 2629 E Rose Garden Lane, Phoenix, AZ 85050

Caleb M. Schmidt and Michael A. Schmidt: Advanced Pattern Analysis \& Countermeasures Group, 2585 Central Avenue, Suite 100, Boulder, CO 80301

\section{References}

1. Daneshvar, D.H.; Nowinski, C.J.; McKee, A.C.; Cantu, R.C. The epidemiology of sport-related concussion. Clin. Sports Med.2011, 30,1-17, vii, doi:10.1016/j.csm.2010.08.006.

2. Trojian, T.H.; Wang, D.H.; Leddy, J.J. Nutritional Supplements for the Treatment and Prevention of Sports-Related Concussion-Evidence Still Lacking. Curr. Sports Med. Rep.2017, 16, 247-255, doi:10.1249/JSR.0000000000000387.

3. Stark, K.D.; Van Elswyk, M.E.; Higgins, M.R.; Weatherford, C.A.; Salem, N., Jr Global survey of the omega-3 fatty acids, docosahexaenoic acid and eicosapentaenoic acid in the blood stream of healthy adults. Prog. Lipid Res.2016, 63, 132-152, doi:10.1016/j.plipres.2016.05.001.

4. Harris, W.S.; Pottala, J.V.; Varvel, S.A.; Borowski, J.J.; Ward, J.N.; McConnell, J.P. Erythrocyte omega-3 fatty acids increase and linoleic acid decreases with age: observations from 160,000 patients. Prostaglandins Leukot. Essent. Fatty Acids2013, 88, 257-263, doi:10.1016/j.plefa.2012.12.004.

5. Johnston, D.T.; Deuster, P.A.; Harris, W.S.; Macrae, H.; Dretsch, M.N. Red blood cell omega-3 fatty acid levels and neurocognitive performance in deployed U.S. Servicemembers. Nutr. Neurosci.2013, 16, 30-38, doi:10.1179/1476830512Y.0000000025. 
6. Meyer, B.J.; Byrne, M.K.; Collier, C.; Parletta, N.; Crawford, D.; Winberg, P.C.; Webster, D.; Chapman, K.; Thomas, G.; Dally, J.; et al. Baseline omega-3 index correlates with aggressive and attention deficit disorder behaviours in adult prisoners. PLoS One2015, 10, e0120220, doi:10.1371/journal.pone.0120220.

7. Oliver, J.M.; Jones, M.T.; Kirk, K.M.; Gable, D.A.; Repshas, J.T.; Johnson, T.A.; Andréasson, U.; Norgren, N.; Blennow, K.; Zetterberg, H. Effect of Docosahexaenoic Acid on a Biomarker of Head Trauma in American Football. Med. Sci. Sports Exerc.2016, 48, 974-982, doi:10.1249/MSS.0000000000000875.

8. Barrett, E.C.; McBurney, M.I.; Ciappio, E.D. $\omega-3$ fatty acid supplementation as a potential therapeutic aid for the recovery from mild traumatic brain injury/concussion. Adv. Nutr.2014, 5, 268-277, doi:10.3945/an.113.005280.

9. Lewis, M.D. Concussions, Traumatic Brain Injury, and the Innovative Use of Omega-3s. J. Am. Coll. Nutr.2016, 35, 469-475, doi:10.1080/07315724.2016.1150796.

10. Fu, H.-J.; Zhao, L.-B.; Xue, J.-J.; Wu, Z.-X.; Huang, Y.-P.; Liu, W.; Gao, Z. Elevated Serum Homocysteine (Hcy) Levels May Contribute to the Pathogenesis of Cerebral Infarction. J. Mol. Neurosci.2015, 56, 553-561, doi:10.1007/s12031-015-0497-6.

11. Rahmani, A.; Hatefi, M.; Dastjerdi, M.M.; Zare, M.; Imani, A.; Shirazi, D. Correlation Between Serum Homocysteine Levels and Outcome of Patients with Severe Traumatic Brain Injury. World Neurosurg.2016, 87, 507-515, doi:10.1016/j.wneu.2015.09.016.

12. Borrione, P.; Rizzo, M.; Spaccamiglio, A.; Salvo, R.A.; Dovio, A.; Termine, A.; Parisi, A.; Fagnani, F.; Angeli, A.; Pigozzi, F. Sport-related hyperhomocysteinaemia: a putative marker of muscular demand to be noted for cardiovascular risk. Br. J. Sports Med.2008, 42, 894-900, doi:10.1136/bjsm.2007.045021.

13. Balion, C.; Griffith, L.E.; Strifler, L.; Henderson, M.; Patterson, C.; Heckman, G.; Llewellyn, D.J.; Raina, P. Vitamin D, cognition, and dementia: a systematic review and meta-analysis. Neurology2012, 79, 1397-1405, doi:10.1212/WNL.0b013e31826c197f.

14. Shirazi, H.A.; Rasouli, J.; Ciric, B.; Rostami, A.; Zhang, G.-X. 1,25-Dihydroxyvitamin D3 enhances neural stem cell proliferation and oligodendrocyte differentiation. Exp. Mol. Pathol.2015, 98, 240-245, doi:10.1016/j.yexmp.2015.02.004.

15. Villacis, D.; Yi, A.; Jahn, R.; Kephart, C.J.; Charlton, T.; Gamradt, S.C.; Romano, R.; Tibone, J.E.; Hatch, G.F.R., 3rd Prevalence of Abnormal Vitamin D Levels Among Division I NCAA Athletes. Sports Health2014, 6, 340-347, doi:10.1177/1941738114524517.

16. Ogan, D.; Pritchett, K. Vitamin D and the athlete: risks, recommendations, and benefits. Nutrients2013, 5, 1856-1868, doi:10.3390/nu5061856.

17. de Baaij, J.H.F.; Hoenderop, J.G.J.; Bindels, R.J.M. Magnesium in man: implications for health and disease. Physiol. Rev.2015, 95, 1-46, doi:10.1152/physrev.00012.2014.

18. Malliaropoulos, N.; Tsitas, K.; Porfiriadou, A.; Papalada, A.; R Ames, P.; Del Buono, A.; Lippi, G.; Maffulli, N. Blood phosphorus and magnesium levels in 130 elite track and field athletes. Asian J. 
Sports Med.2013, 4, 49-53, doi:10.5812/asjsm.34531.

19. von Schacky, C.; Kemper, M.; Haslbauer, R.; Halle, M. Low Omega-3 Index in 106 German elite winter endurance athletes: a pilot study. Int. J. Sport Nutr. Exerc. Metab.2014, 24, 559-564, doi:10.1123/ijsnem.2014-0041.

20. Holub, B.J.; Wlodek, M.; Rowe, W.; Piekarski, J. Correlation of omega-3 levels in serum phospholipid from 2053 human blood samples with key fatty acid ratios. Nutr. J.2009, 8, 58, doi:10.1186/14752891-8-58.

21. Lowering blood homocysteine with folic acid based supplements: meta-analysis of randomised trials. Homocysteine Lowering Trialists' Collaboration. BMJ1998, 316, 894-898.

22. Schmidt, M.A.; Goodwin, T.J. Personalized medicine in human space flight: using Omics based analyses to develop individualized countermeasures that enhance astronaut safety and performance. Metabolomics2013, 9, 1134-1156, doi:10.1007/s11306-013-0556-3.

23. Yi, L.; Shi, S.; Wang, Y.; Huang, W.; Xia, Z.-A.; Xing, Z.; Peng, W.; Wang, Z. Serum Metabolic Profiling Reveals Altered Metabolic Pathways in Patients with Post-traumatic Cognitive Impairments. Sci. Rep.2016, 6, 21320, doi:10.1038/srep21320.

24. Hao, L.; Chen, L.; Sai, X.; Liu, Z.; Yang, G.; Yan, R.; Wang, L.; Fu, C.; Xu, X.; Cheng, Z.; et al. Synergistic effects of elevated homocysteine level and abnormal blood lipids on the onset of stroke. Neural Regeneration Res.2013, 8, 2923-2931, doi:10.3969/j.issn.1673-5374.2013.31.005.

25. Dash, P.K.; Hergenroeder, G.W.; Jeter, C.B.; Choi, H.A.; Kobori, N.; Moore, A.N. Traumatic Brain Injury Alters Methionine Metabolism: Implications for Pathophysiology. Front. Syst. Neurosci.2016, 10, 36, doi:10.3389/fnsys.2016.00036.

26. Kriebitzsch, C.; Verlinden, L.; Eelen, G.; van Schoor, N.M.; Swart, K.; Lips, P.; Meyer, M.B.; Pike, J.W.; Boonen, S.; Carlberg, C.; et al. 1,25-dihydroxyvitamin D3 influences cellular homocysteine levels in murine preosteoblastic MC3T3-E1 cells by direct regulation of cystathionine $\beta$-synthase. J. Bone Miner. Res.2011, 26, 2991-3000, doi:10.1002/jbmr.493.

27. Jamall, O.A.; Feeney, C.; Zaw-Linn, J.; Malik, A.; Niemi, M.E.K.; Tenorio-Jimenez, C.; Ham, T.E.; Jilka, S.R.; Jenkins, P.O.; Scott, G.; et al. Prevalence and correlates of vitamin D deficiency in adults after traumatic brain injury. Clin. Endocrinol. 2016, 85,636-644, doi:10.1111/cen.13045.

28. Kahraman, S.; Ozgurtas, T.; Kayali, H.; Atabey, C.; Kutluay, T.; Timurkaynak, E. Monitoring of serum ionized magnesium in neurosurgical intensive care unit: preliminary results. Clin. Chim. Acta2003, 334, 211-215, doi:10.1016/s0009-8981(03)00235-3.

29. Arango, M.F.; Bainbridge, D. Magnesium for acute traumatic brain injury. Cochrane Database Syst. Rev.2008, CD005400, doi:10.1002/14651858.CD005400.pub3.

30. Westermaier, T.; Stetter, C.; Vince, G.H.; Pham, M.; Tejon, J.P.; Eriskat, J.; Kunze, E.; Matthies, C.; Ernestus, R.-I.; Solymosi, L.; et al. Prophylactic intravenous magnesium sulfate for treatment of aneurysmal subarachnoid hemorrhage: a randomized, placebo-controlled, clinical study. Crit. Care Med.2010, 38, 1284-1290, doi:10.1097/CCM.0b013e3181d9da1e. 